\title{
ASPECTOS FLORÍSTICOS DE TRÊS ESTÁGIOS SUCESSIONAIS EM MATA CILIAR EM ARROIO DO PADRE, EXTREMO SUL DO BRASIL
}

\author{
Tiago Schuch Venzke ${ }^{1}$, Sebastião Venâncio Martins ${ }^{2}$ \\ ${ }^{1}$ Ecólogo, M.Sc., UFV, Viçosa, MG, Brasil - venzke.tiago@gmail.com \\ ${ }^{2}$ Eng. Florestal, Dr., Depto. de Engenharia Florestal, UFV, Viçosa, MG, Brasil - venancio@ufv.br
}

Recebido para publicação: 25/02/2012 - Aceito para publicação: 18/02/2013

\begin{abstract}
Resumo
O objetivo foi caracterizar a composição e as relações florísticas de estágios sucessionais de uma mata ciliar em um fragmento de Floresta Estacional Semidecidual no Município de Arroio do Padre, extremo sul do Brasil. A área amostral foi 1,2 ha, dividida em 0,2 ha para capoeira (5 anos de regeneração), 0,5 ha para floresta secundária (45 anos de regeneração) e 0,5 ha de floresta madura. Em parcelas de 10 x 10 m, foram amostrados todos os indivíduos arbustivo-arbóreos com DAP $\geq 5 \mathrm{~cm}$. A riqueza nos três estágios sucessionais revelou 72 espécies, distribuídas em 52 gêneros e 33 famílias. A capoeira apresentou menor número de táxons, enquanto na fase madura ocorreram maior quantidade (49) e riqueza de espécies exclusivas (20). A composição florística foi influenciada pelo estágio sucessional, e a classificação das parcelas pela análise de similaridade formou agrupamentos conforme a idade da regeneração. Isso reflete a adaptação da comunidade às condições ambientais proporcionadas pelo avanço da sucessão ecológica. Assim, recomenda-se que as estratégias de restauração florestal considerem as espécies adaptadas ao estágio sucessional, a fim de maximizar os projetos de reflorestamento e restauração ecológica.

Palavras-chave: Pelotas; Floresta Estacional Semidecidual; sucessão florestal; ecologia florestal.
\end{abstract}

\begin{abstract}
Floristic composition of three successional stages of a riparian forest in the municipality of Arroio do Padre, very south of Brazil. This research aims to characterize composition and floristic relations of three successional stages of a Riparian Semi-deciduous Seasonal Forest, in the municipality of Arroio do Padre, South of Brazil. The sample area was divided into 0.2 ha for 'capoeira' (five years of regeneration), 0.5 ha for secondary forest (45 years for regeneration), and 0.5 ha for mature forest (primary forest). Richness in the three succession stages included 72 species distributed into 52 genera and 33 families. 'Capoeira' presented lower quantity of taxa, whereas in the mature forest occurred greater number of species (49) and exclusive species (20). The floristic composition was influenced by successional stage and classification of plots by the similarity analysis clusters formed as the regeneration time. Differences in floristic composition reflect community adaptation to the conditions provided along succession. These variations reveal that the age of the succession reflects in forest floristic, and strategies for forest restoration should consider species adapted to successional stages in order to maximize native forests reforestation projects.

Keywords: Municipality of Pelotas; Semi-deciduous Seasonal Forest; forest ecology.
\end{abstract}

\section{INTRODUÇÃO}

O domínio do bioma Mata Atlântica engloba uma área de $1.306 .000 \mathrm{~km}^{2}$, cerca de $15 \%$ do território nacional brasileiro, cobrindo total ou parcialmente 17 estados, e corresponde a um mosaico de ecossistemas florestais e outros ecossistemas associados, como restingas e manguezais, entre outros, que formavam um grande contínuo florestal na época do descobrimento do Brasil, conforme o Conselho Nacional da Reserva da Biosfera da Mata Atlântica (RBMA, 2004). Depois do vasto domínio da Floresta Amazônica, a Floresta Atlântica é a segunda maior área de floresta tropical úmida da América do Sul (OLIVEIRA-FILHO; FONTES, 2000).

No Rio Grande do Sul, a vegetação florestal tropical do domínio Mata Atlântica ocorre em quatro regiões fitoecológicas, conforme classificação do Instituto Brasileiro de Geografia e Estatística (IBGE, 1986): a Floresta Ombrófila Mista, popularmente conhecida como Floresta com Araucária; a 
Floresta Ombrófila Densa (Mata Atlântica stricto sensu); a Floresta Estacional Decidual, caracterizada por um estrato emergente decíduo de indivíduos de Apuleia leiocarpa (Vogel) J. F. Macbr. E de Parapiptadenia rigida (Benth.) Brenan; e a formação, objeto deste estudo, a Floresta Estacional Semidecidual.

A denominação de Estacional Semidecidual é atribuída à deciduidade da floresta, que pode variar entre 20 a $50 \%$ dos indivíduos da comunidade (IBGE, 1986). A caducidade responde a um clima sazonal com um período desfavorável do ano, no qual parte das árvores do dossel perdem as folhas em virtude das estações climáticas bem marcadas, sendo uma chuvosa e outra de longo período seco (IVANAUSKAS; ASSIS, 2009). Porém a Floresta Estacional Semidecidual no Rio Grande do Sul não é afetada por um período seco anual, já que na região a precipitação é constante ao longo do ano e normalmente não apresenta meses com déficit hídrico (EMBRAPA/UFPEL, 2011). Desse modo, o fator sazonal limitante da vegetação são as baixas temperaturas e as geadas ocorridas no inverno. Independentemente da classificação nomenclatural, essa fisionomia florestal está distribuída na vertente leste da província geomorfológica do Escudo Sul-Riograndense, colonizando as porções voltadas para o Oceano Atlântico.

Os fragmentos florestais estão espalhados em paisagens antrópicas e são pequenos, altamente perturbados, geralmente isolados e pouco protegidos, como observado para a Mata Atlântica (VIANA, 1995). Os fragmentos de florestas primárias ou em estágio avançado da sucessão estão distribuídos principalmente em ambientes de topografia acidentada, áreas pedregosas sem serventia para a agricultura e fundo das propriedades. Apesar da atual expansão das áreas de Floresta Estacional Semidecidual no Rio Grande do Sul (CORDEIRO; HASENACK, 2009), elas estão em estágios iniciais da regeneração, caracterizados pela baixa diversidade e composição da flora de espécies pioneiras e/ou generalistas quanto às condições ambientais (VENZKE, 2012).

Nas áreas em regeneração, ocorre o processo da sucessão secundária, que é o mecanismo de autorrenovação das florestas tropicais, através da cicatrização de locais perturbados que ocorrem a cada momento em diferentes locais da mata (GOMEZ-POMPA, 1971). Em virtude dos impactos antrópicos que degradam as paisagens e, consequentemente, os ecossistemas florestais, a época atual é denominada de "era da vegetação secundária" (VACCARO et al., 1999). Contudo, essas florestas secundárias são um importante laboratório natural capaz de gerar informações indispensáveis ao manejo, uso, recuperação e conservação da Floresta Atlântica (TABARELLI et al., 1993).

Em linhas gerais, as pesquisas de sucessão florestal no Brasil são realizadas por meio de duas metodologias principais. O primeiro método verifica a variação da florística e da estrutura da vegetação ao longo do tempo numa mesma área (PAULA et al., 2002; RUSCHEL et al., 2009; MIGUEL et al., 2011; SAWCZUK et al., 2012). Entretanto esse tipo de metodologia apresenta limitações, pois requer um espaço de tempo demasiadamente longo de observação do processo da sucessão (VACCARO et al., 1999). A outra metodologia consiste em comparar áreas de diferentes idades conhecidas e localizadas em sítios ambientais semelhantes (TABARELLI; MANTOVANI, 1999; VACCARO et al., 1999; SIMINSKI et al., 2004; COELHO et al., 2003; PINTO et al., 2007; BRAGA et al., 2011).

Contudo vale lembrar que são escassos os estudos da sucessão florestal na Floresta Estacional Semidecidual do Rio Grande do Sul e que pesquisas sobre a florística e a ecologia das comunidades arbóreas de matas ciliares são fundamentais para embasar quaisquer iniciativas no sentido de proteger, enriquecer, recuperar ou reconstituir a vegetação (OLIVEIRA-FILHO et al., 1994). As listas florísticas de dada microrregião podem subsidiar a escolha de espécies para a recuperação de áreas degradadas, por registrar as espécies que ocorrem em dado ambiente ou local (MORO; MARTINS, 2011). Dessa forma, o objetivo deste estudo foi descrever a composição e as relações florísticas do componente arbóreoarbustivo de três estágios sucessionais de mata ciliar em um fragmento de Floresta Estacional Semidecidual no município de Arroio do Padre, RS, extremo sul do Brasil.

\section{MATERIAL E MÉTODOS}

\section{Área de estudo}

O estudo foi realizado nas nascentes do curso de água do Arroio Andrade, afluente da Bacia Hidrográfica do Arroio Pelotas, que é reconhecido como patrimônio cultural do estado do Rio Grande do Sul (RS, 2003b). A área amostral localiza-se em um fragmento contínuo de aproximadamente 200 ha de Floresta Estacional Semidecidual (IBGE, 1986) no Município de Arroio do Padre, RS, Brasil (31 ${ }^{\circ} 26^{\prime} 19^{\prime \prime}$ S e 52²8'12” O), altitude de 200 m (Figura 1). Essa formação florestal recobre as vertentes 
da Serra dos Tapes, acima da qual predomina uma vegetação campestre herbáceo-arbustiva (HEIDEN; IGANCI, 2009).

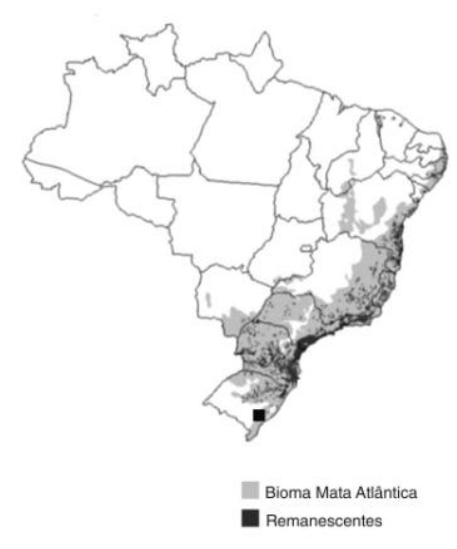

$0 \quad 400 \quad 800$
$-\quad-\quad K m$

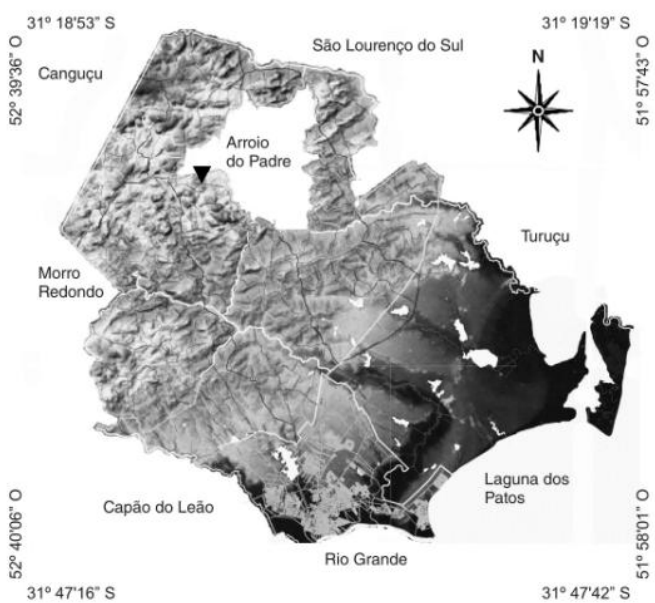

$6 \mathrm{Km}$

Figura 1. Mapa de localização da área de estudo situada no extremo sul da Mata Atlântica ( $\mathbf{\nabla})$.

Figure 1. Location map of the focused area located in the very south of Atlantic Forest $(\boldsymbol{\nabla})$.

Fonte: Reserva da Biosfera da Mata Atlântica e adaptado de mapa rural da Prefeitura Municipal de Pelotas, RS, Brasil, 2011.

O clima da região é do tipo Cfa, conforme a classificação do sistema de Köppen (1948), com temperaturas do mês mais frio entre -3 e $18{ }^{\circ} \mathrm{C}$ e temperatura média do mês mais quente superior a $22^{\circ} \mathrm{C}$. Na região, a temperatura média anual é de $17,8^{\circ} \mathrm{C}$, sendo as médias mensais de $23,2^{\circ} \mathrm{C}$ para o mês mais quente (janeiro) e $12,4{ }^{\circ} \mathrm{C}$ para o mês mais frio (julho), conforme dados do convênio Empresa Brasileira de Pesquisa Agropecuária e Universidade de Federal de Pelotas (EMBRAPA/UFPEL, 2011). O número de dias com geadas é de 23,9 por ano, concentrados entre os meses de maio e setembro (EMBRAPA/UFPEL, 2011). A precipitação pluviométrica média anual é $1.367 \mathrm{~mm}$ e normalmente não ocorrem meses com déficit hídrico. As menores precipitações ocorrem em março $(97,4 \mathrm{~mm})$ e em novembro $(99,5 \mathrm{~mm})$; as maiores em fevereiro e em julho, com 153,3 $\mathrm{mm}$ e $146 \mathrm{~mm}$, respectivamente (EMBRAPA/UFPEL, 2011).

A área do estudo está localizada sobre a encosta leste da província geomorfológica do Escudo Sul-Riograndense, que é a mais antiga do relevo no estado do Rio Grande do Sul. Na região, o relevo é ondulado a forte ondulado desde $100 \mathrm{~m}$ até uma altitude de $400 \mathrm{~m}$ e formado principalmente por rochas graníticas com associação de rochas metamórficas (STRECK et al., 2008). O fragmento do estudo está inserido em região com o granito como material de origem, e os solos são classificados, conforme Streck et al. (2008), em dois tipos: Luvissolo Háplico Órtico e Neossolo Regolítico Distro-Úmbrico.

\section{Amostragem da vegetação}

A amostragem foi realizada em três áreas distintas por meio de 120 parcelas de $10 \mathrm{~m}$ x $10 \mathrm{~m}$, totalizando área amostral de 1,2 ha. Desse montante de parcelas, 50 foram instaladas na floresta madura $(0,5 \mathrm{ha}), 50$ na floresta secundária $(0,5 \mathrm{ha})$ e outras 20 parcelas na área de capoeira $(0,2 \mathrm{ha})$. As parcelas permanentes e contíguas estão localizadas ao longo do mesmo córrego de água. As áreas em regeneração (secundária e capoeira) eram antigas lavouras usadas para cultivos anuais, como fumo, feijão, milho, soja e abóbora, entre outros. Essas áreas ficavam abandonadas durante períodos de 1 a 3 anos. A área "madura" é uma floresta primária onde não ocorreu o corte raso da vegetação, porém houve corte seletivo de espécies de valor madeireiro, como Myrcia glabra (O. Berg.) D Legr., Cordia americana (L.) Gottschling \& J. E. Mill., Cedrela fissilis Vell. e Cabralea canjerana (Vell.) Mart. A área denominada "secundária" está em regeneração natural há cerca de 45 anos, e a "capoeira", abandonada há 5 anos. O critério de inclusão dos indivíduos arbustivo-arbóreos foi de perímetro igual ou superior a $15,8 \mathrm{~cm}$ de perímetro do fuste à altura do peito (PAP). 
A partir da lista das plantas, foi montado o diagrama de Venn, evidenciando espécies em comuns e exclusivas entre os estágios sucessionais. A lista das espécies e as relações de similaridade florística foram geradas pelo programa "Fitopac 2" (SHEPHERD, 1995). Para a análise de similaridade florística, foi elaborado um banco de dados de presença e ausência de espécies nas parcelas. Na classificação das parcelas, usou-se o coeficiente da Distância Euclidiana Simples, pelo qual o valor mais baixo significa que a similaridade entre as amostras é maior, sendo zero o valor mais baixo, representando uma similaridade completa (FELFILI et al., 2011). Por meio desse índice, foi elaborado o dendrograma de agrupamento com base na média de grupo, Unweighted Pair Groups Method using Arithmetic Averages (UPGMA).

A identificação botânica foi realizada em campo, além de comparações no Herbário PEL da Universidade Federal de Pelotas e confirmação em bibliografia específica. A lista florística está organizada pelas famílias do Angiosperm Phylogeny Group III (APG, 2009) e a definição da nomeclatura das espécies e seus identificadores ocorreram conforme o International Plant Name Index (IPNI, 2010).

\section{RESULTADOS}

A riqueza amostrada constitui-se de 72 espécies, distribuídas em 52 gêneros e 33 famílias (Tabela 2). Os gêneros e as famílias mais numerosas em espécies estão descritos na tabela 1. Espécies ameaçadas de extinção foram Cedrela fissilis, Ilex paraguariensis A. St.-Hil., conforme a International Union for Conservation Nature (IUCN, 2008), e Gochnatia polymorpha (Less.) Cabrera, oficialmente ameaçada de extinção, conforme Lista Final da Flora Ameaçada para o estado do Rio Grande do Sul (RS, 2003a).

$\mathrm{Na}$ capoeira, os gêneros representativos foram Myrsine (3), Ilex e Ocotea (2). Na área em regeneração de 45 anos, foram Myrsine (4), Casearia, Ilex, Miconia, Myrcia, Ocotea e Zanthoxylum (2). $\mathrm{Na}$ floresta madura, os gêneros mais ricos foram Myrsine (3), Banara, Casearia, Chrysophyllum, Eugenia, Ficus e Trichilia (2).

Tabela 1. Relação dos táxons mais representativos em espécies em 1,2 ha de mata ciliar no município de Arroio do Padre, RS, Brasil.

Table 1. List of taxa most representative in species in 1.2 ha of riparian forest in the municipality of Arroio do Padre, RS, Brazil.

\begin{tabular}{lccc}
\hline Riqueza & Família & Riqueza & Gênero \\
\hline 8 & Myrtaceae & 4 & Myrsine \\
5 & Salicaceae & 3 & Ilex e Ficus \\
4 & Euphorbiaceae, Lauraceae, Meliaceae, & 2 & Cordia, Ocotea, Miconia, Trichilia, \\
& Moraceae, Primulaceae e Sapindaceae & & Eugenia, Myrcia, Zanthoxylum, \\
3 & Aquifoliaceae e Asteraceae & & Banara, Casearia, Chrysophyllum \\
\hline
\end{tabular}

Quanto às famílias mais ricas, encontraram-se, na capoeira, Lauraceae, Primulaceae, Myrtaceae e Sapindaceae (3), e na floresta secundária, Myrtaceae (5), Primulaceae (4), Euphorbiaceae, Lauraceae, Salicaceae e Sapindaceae (3). Já na área de floresta madura, as famílias mais numerosas foram: Myrtaceae e Salicaceae (5), Meliaceae (4) e Euphorbiaceae, Lauraceae, Moraceae e Primulaceae (3). A riqueza foi maior na floresta madura, com 49 espécies, e menor na capoeira, com 30 espécies (Figura 2).

Na mata ciliar ocorreu a variação da composição da flora ao longo da sucessão. Ao redor do fragmento nas pastagens e nas lavouras abandonadas recentemente (1-3 anos), predominam na regeneração natural arbustos da família Asteraceae (Baccharis articulata Pers. e Baccharis dracunculifolia DC.), a espécie Escallonia bifida Link \& Otto ex Engl. e plântulas das famílias Anacardiaceae, Primulaceae, Quillajaceae, Salicaceae e Sapindaceae.

No estágio capoeira, os arbustos do gênero Baccharis foram substituídos pela população de Escallonia bifida. Nesse momento, já é proporcionado maior sombreamento do solo. Surgem também indivíduos jovens de Allophylus edulis Niederl., Matayba elaeagnoides Radlk., Myrsine laetevirens (Mez) Arechav., Cupania vernalis Cambess., Casearia sylvestris Sw., Xylosma pseudosalzmannii Sleumer, Syagrus romanzoffiana (Cham.) Glassman, Myrsine umbellata Mart., Lithraea brasiliensis Marchand e Ocotea puberula (Rich.) Nees. 
Tabela 2. Relação das espécies amostradas em três estágios sucessionais de uma mata ciliar no município de Arroio do Padre, extremo sul do Brasil.

Table 2. List of species sampled in three successional stages of a riparian forest in the municipality of Arroio do Padre, very south of Brazil.

\begin{tabular}{|c|c|c|c|}
\hline Famílias/Espécie & Capoeira & Secundária & Madura \\
\hline \multicolumn{4}{|l|}{ ANACARDIACEAE } \\
\hline Lithraea brasiliensis Marchand & $\mathrm{x}$ & $\mathrm{x}$ & \\
\hline Schinus polygamus (Cav.) Cabrera & $\mathrm{x}$ & $\mathrm{x}$ & \\
\hline \multicolumn{4}{|l|}{ ANNONACEAE } \\
\hline Annona sylvatica A. St.-Hil. & $\mathrm{x}$ & & $x$ \\
\hline \multicolumn{4}{|l|}{ AQUIFOLIACEAE } \\
\hline Ilex brevicuspis Reissek & $\mathrm{x}$ & $\mathrm{x}$ & \\
\hline Ilex dumosa Reissek & $\mathrm{x}$ & & \\
\hline Ilex paraguariensis A. St.-Hil. & & $x$ & $x$ \\
\hline \multicolumn{4}{|l|}{ ARALIACEAE } \\
\hline Schefflera morototoni (Aubl.) Maguire, Steyerm. \& Frodin & & & $x$ \\
\hline \multicolumn{4}{|l|}{ ARECACEAE } \\
\hline Syagrus romanzoffiana (Cham.) Glassman & $\mathrm{x}$ & $\mathrm{x}$ & $\mathrm{x}$ \\
\hline \multicolumn{4}{|l|}{ ASTERACEAE } \\
\hline Dasyphyllum spinescens (Less.) Cabrera & $\mathrm{x}$ & & \\
\hline Gochnatia polymorpha (Less.) Cabrera & & $\mathrm{x}$ & \\
\hline Vernonia discolor (Spreng.) Less. & & & $\mathrm{x}$ \\
\hline \multicolumn{4}{|l|}{ BORAGINACEAE } \\
\hline Cordia americana (L.) Gottschling \& J. S. Mill. & & $x$ & \\
\hline Cordia ecalyculata Vell. & & & $\mathrm{x}$ \\
\hline \multicolumn{4}{|l|}{ CARDIOPTERIDACEAE } \\
\hline Citronella paniculata (Mart.) R. A. Howard & & & $x$ \\
\hline \multicolumn{4}{|l|}{ CANNABACEAE } \\
\hline Trema micrantha $($ L.) Blume & $x$ & & $x$ \\
\hline \multicolumn{4}{|l|}{ CELASTRACEAE } \\
\hline Maytenus glaucencens Reissek & & $\mathrm{x}$ & \\
\hline \multicolumn{4}{|l|}{ CYATHEACEAE } \\
\hline Alsophila setosa Kaulf. & & $\mathrm{x}$ & $\mathrm{x}$ \\
\hline \multicolumn{4}{|l|}{ EBENACEAE } \\
\hline Diospyros inconstans Jacq. & & $\mathrm{x}$ & $\mathrm{x}$ \\
\hline \multicolumn{4}{|l|}{ ELAEOCARPACEAE } \\
\hline Sloanea monosperma Vell. & & $x$ & $x$ \\
\hline \multicolumn{4}{|l|}{ ESCALLONIACEAE } \\
\hline Escallonia bifida Link \& Otto & $x$ & $x$ & \\
\hline \multicolumn{4}{|l|}{ EUPHORBIACEAE } \\
\hline Actinostemon concolor (Spreng.) Müll. Arg. & & $\mathrm{x}$ & $x$ \\
\hline Alchornea triplinervia (Spreng.) Müll. Arg. & $\mathrm{x}$ & $\mathrm{x}$ & $\mathrm{x}$ \\
\hline Sapium glandulosum (L.) Morong & & $\mathrm{x}$ & \\
\hline \multirow{2}{*}{\multicolumn{4}{|c|}{ LAMIACEAE }} \\
\hline & & & \\
\hline Vitex megapotamica (Spreng.) Moldenke & & & $x$ \\
\hline \multicolumn{4}{|l|}{ LAURACEAE } \\
\hline Aiouea saligna Meisn. & & & $\mathrm{x}$ \\
\hline Nectandra megapotamica (Spreng.) Mez & $\mathrm{x}$ & $\mathrm{x}$ & $\mathrm{x}$ \\
\hline Ocotea puberula (Rich.) Nees & $x$ & $x$ & $x$ \\
\hline \multirow{2}{*}{\multicolumn{4}{|c|}{ MELASTOMATACEAE }} \\
\hline & & & \\
\hline Miconia hyemalis A. St.-Hil. \& Naudin & $\mathrm{x}$ & $\mathrm{x}$ & \\
\hline Miconia pusilliflora (DC.) Naudin & & $\mathrm{x}$ & $\mathrm{x}$ \\
\hline
\end{tabular}

FLORESTA, Curitiba, PR, v. 43, n. 2, p. 191 - 204, abr. / jun. 2013. 


\begin{tabular}{|c|c|c|c|}
\hline \multicolumn{4}{|l|}{ MELIACEAE } \\
\hline Cabralea canjerana (Vell.) Mart. & $\mathrm{x}$ & $x$ & $\mathrm{x}$ \\
\hline Cedrela fissilis Vell. & & $\mathrm{x}$ & $\mathrm{x}$ \\
\hline Trichilia claussenii C. DC. & & & $x$ \\
\hline Trichilia elegans A. Juss. & & & $x$ \\
\hline \multicolumn{4}{|l|}{ MORACEAE } \\
\hline Ficus luschnathiana Miq. & & & $\mathrm{x}$ \\
\hline Ficus organensis Miq. & $\mathrm{x}$ & & $x$ \\
\hline Ficus sp. & & $x$ & \\
\hline Sorocea bonplandii (Baill.) W. C. Burger, Lanj. \& Boer & & & $\mathrm{x}$ \\
\hline \multicolumn{4}{|l|}{ MYRTACEAE } \\
\hline Blepharocalyx salicifolius (Kunth) O. Berg & $\mathrm{x}$ & $x$ & \\
\hline Campomanesia xanthocarpa $\mathrm{O}$. Berg. & & & $\mathrm{x}$ \\
\hline Eugenia rostrifolia D. Legrand & & & $x$ \\
\hline Eugenia schuechiana $\mathrm{O}$. Berg. & & $x$ & $x$ \\
\hline Myrcia glabra (O. Berg.) D. Legrand & & $\mathrm{x}$ & $x$ \\
\hline Myrcia palustris DC. & & $x$ & \\
\hline Myrcianthes gigantea (D. Legrand) D. Legrand & & & $x$ \\
\hline Psidium cattleianum Sabine & $\mathrm{x}$ & $x$ & \\
\hline \multicolumn{4}{|l|}{ NYCTAGINACEAE } \\
\hline Guapira opposita (Vell.) Reitz & $\mathrm{x}$ & $x$ & $x$ \\
\hline cf Pisonia ambigua Heimerl & & & $x$ \\
\hline \multicolumn{4}{|l|}{ PRIMULACEAE } \\
\hline Myrsine coriacea (Sw.) R. Br. & $\mathrm{x}$ & $x$ & \\
\hline Myrsine laetevirens (Mez) Arechav & $\mathrm{x}$ & $x$ & $x$ \\
\hline Myrsine umbellata Mart. & $\mathrm{x}$ & $x$ & $x$ \\
\hline Myrsine sp. & & $\mathrm{x}$ & $x$ \\
\hline \multicolumn{4}{|l|}{ QUILLAJACEAE } \\
\hline Quillaja brasiliensis Mart. & & $x$ & \\
\hline \multicolumn{4}{|l|}{ ROSACEAE } \\
\hline Prunus myrtifolia (L.) Urb. & & & $x$ \\
\hline \multicolumn{4}{|l|}{ RUBIACEAE } \\
\hline Faramea montevidensis (Cham. \& Schltdl.) DC. & & $x$ & $x$ \\
\hline \multicolumn{4}{|l|}{ RUTACEAE } \\
\hline Zanthoxylom fagara (L.) Sarg. & $x$ & $x$ & \\
\hline Zanthoxylum rhoifolium Lam. & & $x$ & $x$ \\
\hline \multicolumn{4}{|l|}{ SALICACEAE } \\
\hline Banara parviflora (A. Gray) Benth & & & $\mathrm{x}$ \\
\hline Banara tomentosa $\mathrm{Clos}$ & & & $x$ \\
\hline Casearia decandra Jacq. & & $x$ & $x$ \\
\hline Casearia sylvestris $\mathrm{Sw}$. & $x$ & $x$ & $x$ \\
\hline Xylosma pseudosalzmannii Sleumer & $\mathrm{x}$ & $x$ & $x$ \\
\hline \multicolumn{4}{|l|}{ SAPINDACEAE } \\
\hline Allophylus edulis (A.St.-Hil.) Niederl. & $x$ & $x$ & $x$ \\
\hline Cupania vernalis Cambess. & $x$ & & $x$ \\
\hline Dodonaea viscosa Jacq. & & $x$ & \\
\hline Matayba elaeagnoides Radlk. & $x$ & $x$ & \\
\hline \multicolumn{4}{|l|}{ SAPOTACEAE } \\
\hline Chrysophyllum gonocarpum (Mart. \& Eichler ex Miq.) Engl. & & & $\mathrm{x}$ \\
\hline Chrysophyllum marginatum (Hook. \& Arn.) Radlk. & $\mathrm{x}$ & $\mathrm{x}$ & $\mathrm{x}$ \\
\hline \multicolumn{4}{|l|}{ SOLANACEAE } \\
\hline Solanum sanctaecatharinae Dunal & & & $\mathrm{x}$ \\
\hline \multicolumn{4}{|l|}{ STYRACACEAE } \\
\hline Styrax leprosus Hook. \& Arn. & $\mathrm{x}$ & $\mathrm{x}$ & \\
\hline THYMELAEACEAE & & & \\
\hline Daphnopsis racemosa Griseb. & & $\mathrm{x}$ & \\
\hline
\end{tabular}

Daphnopsis racemosa Griseb.

Capoeira: 5 anos de regeneração; secundária: 45 anos de regeneração; madura: floresta primária sem corte raso e com corte seletivo. 


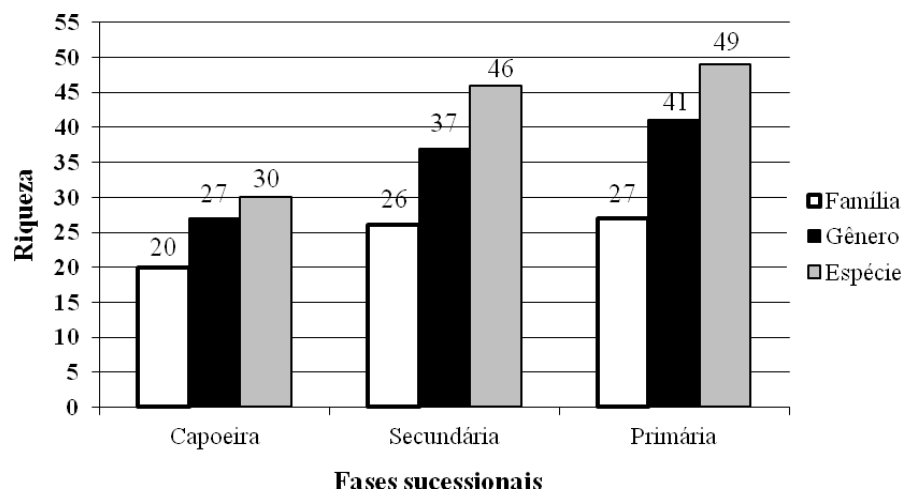

Figura 2. Diversidade de táxons em três estágios sucessionais de mata ciliar em Floresta Estacional Semidecidual, extremo sul da Mata Atlântica, Arroio do Padre, RS, Brasil.

Figure 2. Taxa richness in three successional stages of a Riparian Semideciduous Forest, very south of Atlantic Forest, municipality of Arroio do Padre, RS, Brazil.

Na floresta secundária, Escallonia bifida ainda se encontra entre as principais populações, porém, com uma gama dos indivíduos em fase senil. Nesta etapa, o dossel está formado e a composição da floresta foi caracterizada pelo gênero Myrsine e as espécies Psidium cattleianum Sabine, Ilex brevicuspis Reissek, Lithraea brasiliensis, Blepharocalyx salicifolius (Kunth) O. Berg e Myrcia glabra.

Contudo, a flora na floresta madura é distinta das áreas jovens. O dossel é constituído principalmente por Alchornea triplinervia (Spreng.) Müll. Arg., Myrcia glabra, Ficus luschnathiana Miq., Ficus organensis Miq., Miconia pusilliflora Naudin, Cabralea canjerana e Eugenia rostrifolia D. Legrand. A composição é caracterizada, sem dúvida, pelas espécies adaptadas aos ambientes de sombra no sub-bosque. Como exemplo as populações de Gymnanthes concolor (Spreng.) Müll. Arg., Alsophila setosa Kaulf., Eugenia schuechiana O. Berg, Trichilia claussenii, Miconia pusilliflora, Sorocea bonplandii (Baill.) W. C. Burger, Lanj. \& Boer e Faramea montevidensis (Cham. \& Schltdl.) DC.).

A distribuição das espécies comuns ou exclusivas nos estágios sucessionais está ilustrada no diagrama de Venn da figura 3. A maior riqueza exclusiva ocorreu nas áreas secundária e madura, com respectivamente 9 e 20 espécies. Na capoeira, foram exclusivas apenas duas espécies (Ilex dumosa Reissek e Dasyphyllum spinescens (Less.) Cabrera).

A análise da similaridade florística revelou a formação de dois grandes agrupamentos de parcelas (Figura 4). O mais compacto reuniu as provenientes da floresta madura (grupo D). O segundo foi formado por parcelas das áreas da capoeira e da secundária. Porém foi possível distinguir três subgrupos nas áreas em regeneração (A, B e C): o grupo A, constituído pela floresta com 45 anos de sucessão natural; o grupo B, formado pela área em sucessão há 5 anos; e um terceiro agrupamento (C), de parcelas situadas na floresta secundária e que teve um grau de similaridade menor em relação às demais parcelas em regeneração.

\section{DISCUSSÃO}

A mata ciliar do fragmento em Arroio do Padre teve variação na composição florística entre os estágios sucessionais. Ocorreu também alteração nas principais famílias durante a sucessão. Lauraceae e Myrtaceae, independentemente da região geográfica, proximidade ou altitude da Mata Atlântica, são importantes em áreas primárias ou em estágios avançados da sucessão da Mata Atlântica (TABARELLI; MANTOVANI, 1999; TABARELLI; PERES, 2002; RUSCHEL et al., 2009). A riqueza de Fabaceae, outra família importante em florestas conservadas na Mata Atlântica (PINTO et al., 2007; BRAGA et al., 2011), é poucas espécies na área estudada, como Bauhinia forficata Link, Erythrina crista-galli L. e Mimosa bimucronata (DC.) Kuntze (VENZKE, 2012). Já as famílias Melastomataceae, Rubiaceae, Myrsinaceae e Salicaceae tendem a ser dominantes nas florestas jovens da Floresta Atlântica (TABARELLI; MANTOVANI, 1999; TABARELLI; PERES, 2002; RUSCHEL et al., 2009). Em Arroio do Padre, Melastomataceae é representada por Miconia hiemalis A. St.-Hil. \& Naudin ex Naudin nas 
capoeiras, e Miconia pusilliflora Naudin em ambientes esciófitos. Rubiaceae não é representativa em florestas jovens, ocorrendo comumente como arbustos do gênero Psychotria que habitam o sub-bosque de estágios avançados da sucessão.

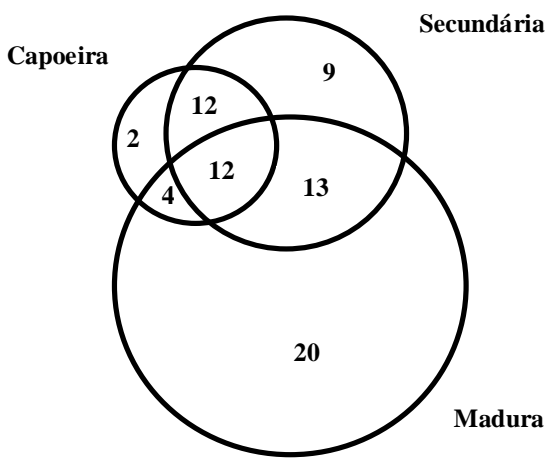

Figura 3. Diagrama de Venn das relações florísticas de três estágios de mata ciliar em Arroio do Padre, RS, Brasil.

Figure 3. Venn diagram of floristic composition of three stages of a Riparian Semideciduous Forest, very south of Atlantic Forest, municipality of Arroio do Padre, RS, Brazil.

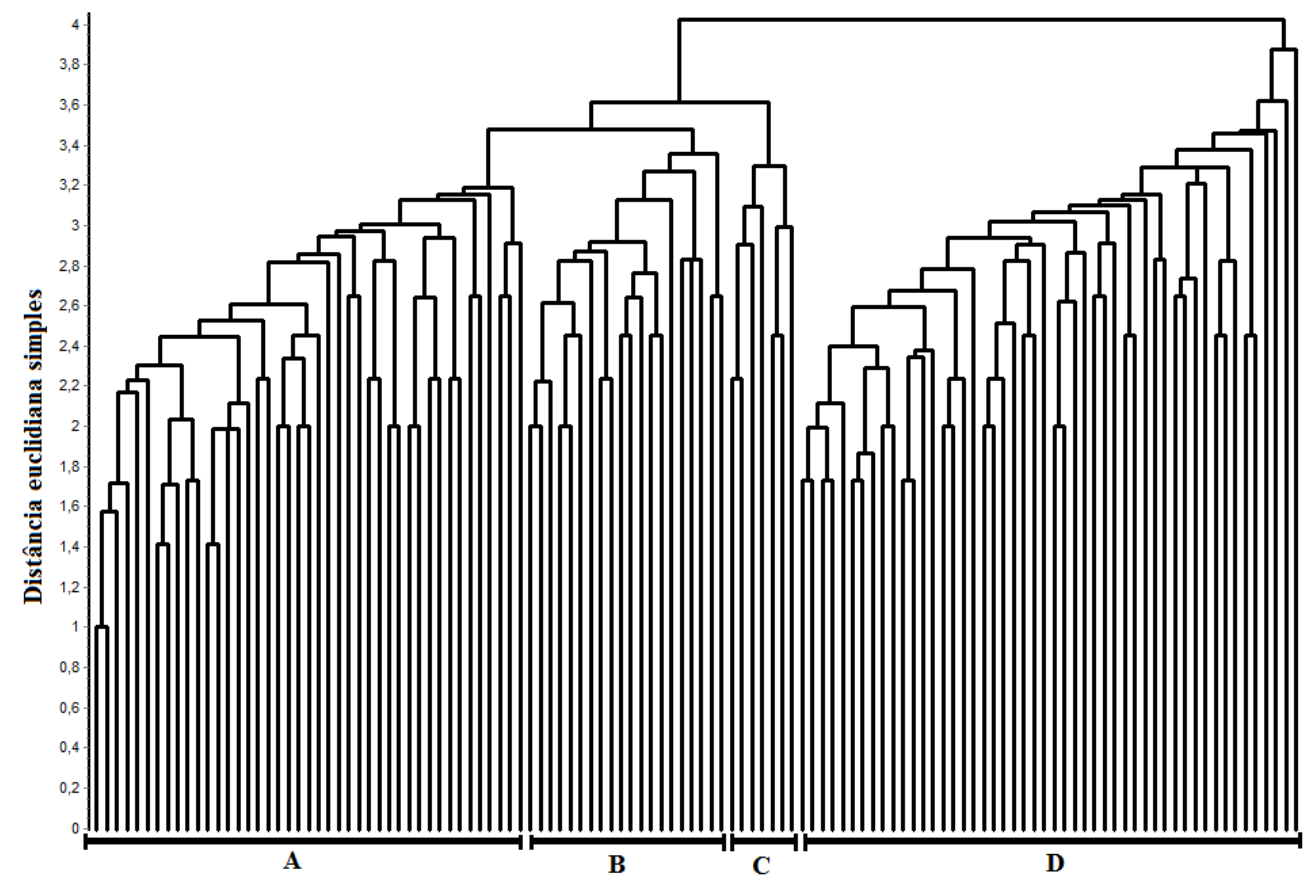

Figura 4. Dendrograma de similaridade da presença e ausência de espécies florestais (DAP $\geq 5 \mathrm{~cm}$ ) em 120 parcelas em estudo florístico de três estágios da sucessão florestal em mata ciliar no município de Arroio do Padre, RS, Brasil.

Figure 4. Dendrogram of similarity with data of presence and absence of tree species $(\mathrm{DBH} \geq 5 \mathrm{~cm})$ in 120 plots on floristic study of three stages of forest succession in the riparian forest in the municipality of Arroio do Padre, RS, Brazil. 
A riqueza de espécies foi maior na floresta madura (49), juntamente com o número de espécies exclusivas (20). No Brasil, estudos de florestas tropicais com estágios sucessionais apresentam diferentes composições florísticas em relação ao tempo de regeneração. Conforme a sucessão da floresta tropical avança, ocorre incremento da riqueza de espécies arbustivo-arbóreas (TABARELLI; MANTOVANI, 1999; COELHO et al., 2003; PINTO et al., 2007; RUSCHEL et al., 2009; MIGUEL et al., 2011; SAWCZUK et al., 2012).

$\mathrm{Na}$ regeneração das florestas neotropicais, a riqueza e as diversidades elevadas parecem ser resultantes da ocorrência simultânea de espécies pioneiras e tolerantes ao sombreamento (LASKA, 1997). Nesse caso, os pequenos distúrbios na floresta primária permitem o estabelecimento de indivíduos de espécies pioneiras ou o aumento dessas populações nas novas clareiras, de modo que a diversidade é aumentada nas florestas primárias (HORN, 1974).

Nos estágios avançados ou primários, ocorre ainda uma complexibilidade na estrutura da vegetação. As espécies arbóreas tropicais necessitam de certas condições microambientais, como ótimos de temperatura, gás carbônico, umidade, vento, abertura e fechamento do dossel (WHITMORE, 2006). Assim, a estratificação vertical do ar e do solo, gradientes físicos do hábitat, alelopatia, diversidade de polinizadores e dispersores e presença de ritmos fenológicos diferenciados são fatores que promovem a diversidade entre as espécies de floresta primária (HORN, 1974).

Outros estudos apontam riqueza de espécies arbustivo-arbóreas levemente elevada em estágios intermediários (VACCARO et al., 1999; SIMINSKI et al., 2004; BRAGA et al., 2011). Essa maior riqueza foi influenciada por condições edáficas. Solos de baixada da área em estágio inicial foram classificados como eutróficos, menos ácidos e com teores de macronutrientes maiores que o solo da floresta avançada. Assim, a posição topográfica da floresta e o tipo de solo sugerem exercer maior influência na fertilidade do solo que o estádio sucessional (BRAGA et al., 2011).

A topografia também influencia a floresta com inundação periódica. Em uma floresta ribeirinha no rio Uruguay, Ghiel e Jarenkow (2008) observaram que inundações frequentes causaram seletividade nas espécies e na estrutura da floresta, ocorrendo a ausência de um dossel típico de no mínimo $10 \mathrm{~m}$ de altura nas áreas em topografia mais baixa. Em florestas nativas, localizadas em latitudes similares no Uruguai, Brussa et al. (1993) encontraram composição de espécies diferenciadas entre as porções localizados no alto das encostas e aquelas encontradas na calha da bacia hidrográfica. Apesar de muitas delas serem comuns a ambos os locais (26), estruturalmente apresentaram diferença nas espécies mais importantes. Ainda, espécies exclusivas foram 12 e 11 no topo e na calha, respectivamente.

A riqueza geral na mata ciliar de Arroio do Padre foi maior que em estudos fitossociológicos de um hectare de Floresta Estacional Semidecidual no Rio Grande do Sul, que variaram de 29 até 69 espécies arbustivo-arbóreas (SOUZA, 2001; KILCA, 2002; JURINITZ; JARENKOW, 2003; DE MARCHI; JARENKOW, 2008). Em 1,83 ha no município de Montenegro, foram anotadas 81 espécies (LONGHI et al., 2008). Na região do extremo sul do Brasil, em levantamentos florísticos efetuados por caminhamento, observou-se riqueza mais elevada, variando de 74 até 89 espécies arbóreas (SOUZA, 2001; KILCA, 2002; VENZKE, 2009; VENZKE, 2012).

A riqueza na floresta madura foi maior que em 1 ha de floresta de encosta preservada no mesmo fragmento, com 45 espécies de DAP $\geq 5 \mathrm{~cm}$ (SOUZA, 2001), refletindo a tendência de maior riqueza em matas ciliares. As formações florestais ciliares possuem características vegetacionais definidas em função da heterogeneidade ambiental, proporcionada pela interação dos fatores físicos, climáticos e biológicos (CATHARINO, 1989). Como exemplo de fatores físicos e climáticos, citam-se a correnteza e a morfogenética dos rios, que moldam um relevo heterogêneo de taludes e canais, juntamente com os diferentes níveis do lençol freático, as temperaturas maiores e mais amenas e a umidade atmosférica no fundo dos vales, causada pela neblina e condensação de vapores de água. Assim, os fatores atuam de forma conjunta ao longo do tempo, criando condições ambientais muito diversas para a ocorrência de florestas às margens dos cursos de água (MANTOVANI, 1989).

Os estágios sucessionais em Arroio do Padre apresentaram ainda uma identidade florística particular (Figura 4). Na Mata Atlântica, ocorrem mudanças nos componentes da vegetação durante regeneração, conforme Tabarelli e Peres (2002), para diferentes métodos, esforço amostral e tamanho de parcelas. As mudanças ambientais ao longo da sucessão ecológica promovem alterações nas relações bióticas da comunidade, que tendem para diversificar as formas de vida; substituir espécies com amplitudes ecológicas similares e amplas por grupos de limites estreitos; aumentar o número de relações 
dependentes e interespecíficas; amenizar os extremos microambientais; maturar o perfil do solo; e dar ao ecossistema maior resistência a distúrbios externos (DAUBENMIRE, 1968). Nos estágios maduros das matas ciliares ocorre maior variedade de nichos, diferentes gradientes de sombreamento e umidade, altura do dossel, fertilidade e topografia do relevo, que proporcionam a ocorrência de uma flora mais diversificada, adaptada ao sub-bosque, às clareiras no dossel, à correnteza e aos diferentes níveis do lençol freático, fato este observado com a maior riqueza da floresta madura em Arroio do Padre.

$\mathrm{Na}$ análise de agrupamento, houve uma dissimilaridade entre as parcelas em regeneração, formando um quarto agrupamento (C). Neste, habitavam indivíduos de Alsophila setosa, Eugenia schuechiana e Miconia pusilliflora, que possuem populações com abundância elevada na floresta madura. Provavelmente, o grupo $\mathrm{C}$ é explicado pela influência da localização dessas parcelas, que estão espacialmente próximas da área de floresta madura, podendo ser considerada uma área de ecótono entre a sucessão secundária e a madura. Assim, pela proximidade espacial, ocorreu influência na dispersão de propágulos da floresta primária para a área em regeneração, em vista de que o processo de dispersão de sementes é essencial para colonização de hábitat e constituição da estrutura espacial e temporal de populações de plantas (BARBOSA et al., 2009). A dispersão significa a ligação entre a última fase reprodutiva da planta com a primeira fase do recrutamento da nova população (GALETTI et al., 2003).

A distinção florística entre os estágios sucessionais tende a ser estreitada com o aumento do sombreamento no estágio inicial. Esse processo é fundamental para a dinâmica da comunidade, para o recrutamento de espécies secundárias tardias e avanço da sucessão (BRAGA et al., 2011), porque, depois de um distúrbio, a sucessão secundária tende a reconstruir uma comunidade parecida com a comunidade original (HORN, 1974).

Algumas espécies foram amostradas nos três estágios, sendo consideradas generalistas ao longo da sucessão florestal. Com populações representativas, merecem destaque Myrsine umbellata, Myrsine laetevirens, Casearia sylvestris Sw., Allophylus edulis, Xylosma pseudosalzmannii Sleumer, Alchornea triplinervia, Cabralea canjerana, Nectandra megapotamica Mez e Ocotea puberula. Essas espécies são potenciais ao uso no reflorestamento e no enriquecimento das capoeiras do extremo sul da Floresta Atlântica, regiões de ocorrência da Floresta Estacional Semidecidual no Rio Grande do Sul.

Finalmente, o avanço da sucessão florestal demonstra que o estágio secundário (45 anos) já possui condições para o estabelecimento de espécies características dos estágios avançados. Em meio às espécies típicas dos estágios iniciais (Myrsine laetevirens, Myrsine umbellata, Psidium cattleianum, Ilex brevicuspis, Lithraea brasiliensis, Blepharocalyx salicifolius, Matayba elaeagnoides, Syagrus romanzoffiana e Escallonia bifida) ocorre o desenvolvimento de espécies típicas dos estágios sucessionais avançados (Eugenia schuechiana, Trichilia claussenii C. DC., Cabralea canjerana e Myrcia glabra, entre outras).

\section{CONCLUSÃO}

A composição florística foi influenciada conforme o estágio sucessional, refletindo a lógica de incremento da biodiversidade de espécies arbustivo-arbóreas conforme o tempo de regeneração. A maior riqueza e espécies exclusivas na floresta madura (clímax) indica que os fragmentos em bom estado de conservação são hábitats importantes para a conservação de espécies arbustivo-arbóreas na paisagem. Muitas delas são tolerantes aos ambientes de sombra no sub-bosque das florestas maduras.

A análise de similaridade indicou a formação de agrupamentos semelhantes entre si, demonstrando que o tempo de regeneração reflete na florística da comunidade. Assim, os resultados mostram que estratégias para a restauração florestal devem considerar a escolha correta das espécies conforme o estágio sucessional, a fim de maximizar os projetos de reflorestamento e restauração ecológica.

\section{REFERÊNCIAS}

ANGIOSPERM PHYLOGENY GROUP III. An update of the Angiosperm Phylogeny Group classification for the orders and families of flowering plants: APG III. Botanical Journal of the Linnean Society, Londres, v. 161, p. 105 - 121, 2009. 
BARBOSA, J. M.; EISENLOHR, P. V.; RODRIGUES, M. A.; BARBOSA, K. C. Ecologia da dispersão de sementes em Florestas Tropicais. In: MARTINS, S. V. Ecologia de Florestas Tropicais do Brasil. Viçosa, 2009. p. 52 - 73.

BRAGA, A. J. T.; BORGES, E. E. L.; MARTINS, S. V. Florística e estrutura da comunidade arbórea de uma Floresta Estacional Semidecidual em Viçosa, MG. Revista Árvore, Viçosa, v. 35, n. 3, p. 493 - 503, 2011.

BRUSSA, C. A.; SANS, C.; MAJO, B.; SORRENTINO, A. Estudio fitosociologico del monte nativo em las nacientes del Arroyo Lunarejo, Departamento de Rivera. Boletim de Investigacion, Montevideu, v. 38, p. 3 - 32, 1993.

CATHARINO, E. L. M. Florística de matas ciliares. In: SIMPÓSIO SOBRE MATA CILIAR, 1989, Campinas. Anais... Campinas: Fundação Cargill, 1989. p. 61 - 70.

COELHO, R. F. R.; ZARIN, D. J.; MIRANDA, I. S.; TUCKER, J. M. Análise florística e estrutural de uma floresta em diferentes estágios sucessionais no município de Castanhal, Pará. Acta Amazonica, Manaus, v. 33, n. 4, p. 563 - 582, 2003.

CONSELHO NACIONAL DA RESERVA DA BIOSFERA DA MATA ATLÂNTICA (RBMA), 2004. Domínio da Mata Atlântica: conceitos e abrangência. Disponível em: <http://www.rbma.org.br/anuario/ mata_02_dma.asp\#>. Acesso em: 08/05/2012.

CORDEIRO, J. L. P.; HASENACK, H. A cobertura vegetal atual do Rio Grande do Sul. In: Campos Sulinos: conservação e uso sustentável da biodiversidade. Brasília: MMA, 2009. p. 285 - 299.

DAUBENMIRE, R. Plant communities: a textbook of plant sinecology. Newyork: Harpen and Row, 1968. $300 \mathrm{p}$.

DE MARCHI, T. C.; JARENKOW, J. A. Estrutura do componente arbóreo de mata ribeirinha no rio Camaquã, município de Cristal, Rio Grande do Sul, Brasil. Iheringia: Série Botânica, Porto Alegre, v. 63, n. 2, p. 241 - 248, 2008.

EMPRESA BRASILEIRA DE PESQUISA AGROPECUÁRIA E UNIVERSIDADE FEDERAL DE PELOTAS (EMBRAPA/UFPEL). Temperatura média $\left({ }^{\circ} \mathrm{C}\right)$ e preciptação pluviométrica $(\mathbf{m m})$ período: 1971/2000 (mensal/anual). Estação Agroclimatológica: Capão do Leão, RS. Convênio Embrapa/UFPel/INMET. Disponível em: 〈http://www.cpact.embrapa.br/agromet/estacao/index.htm>. Acesso em: 28/12/2011.

FELFILI, J. M.; CARVALHO, F. A.; LIBANO, A. M.; VENTUROLI, F.; PEREIRA, B. A. S.; MACHADO, E. L. V. Análise multivariada: princípios e métodos em estudos de vegetação. In: FELFINI, J M.; EISENLOHR, P. V.; MELO, M. M. R. F.; ANDRADE, L. A. A.; NETO, J. A. A. M. Fitossociologia no Brasil: métodos e estudos de caso. Viçosa, 2011. p. 122 - 155.

GALETTI, M.; PIZO, M. A.; MORELlATO, P. C. Fenologia, frugivoria e dispersão de sementes. In: CULLEN JR., L; VALLADARES-PÁDUA, C.; RUDRAN, R. Métodos de estudo em biologia da conservação e manejo da vida silvestre. Curitiba, 2003. p. 395 - 422.

GHIEL, E. L. H.; JARENKOW, J. A. Gradiente estrutural no componente arbóreo e relação com inundações em uma floresta ribeirinha, rio Uruguay, sul do Brasil. Acta Botanica Brasilica, Feira de Santana, v. 22, n. 3, p. $741-753,2008$.

GÓMEZ-POMPA, A. Posible papel de la vegetación secundaria en la evolución de la flora tropical. Biotropica, Lawrence, v. 3, p. 125 - 135, 1971.

HEIDEN, G.; IGANCI, J. R. V. Sobre a paisagem e a flora. In: STUMPF, E. R. T.; BARBIERI, R. L.; HEIDEN, G. Cores e formas no Bioma Pampa: plantas ornamentais nativas. Pelotas, 2009. p. 23 - 35.

HORN, H. S. The ecology of secondary succession. Annual Review Ecology Systematics, Palo Alto, v. 5, p. 25 - 37, 1974. 
INSTITUTO BRASILEIRO DE GEOGRAFIA E ESTATÍSTICA (IBGE). Vegetação: as regiões fitoecológicas, sua natureza e seus recursos econômicos: estudo fitogeográfico. In: TEIXEIRA, M. B.; COURA-NETO A. B.; PASTORE, U.; RANGEL-FILHO, A. L. R. Levantamento de recursos naturais. Rio de Janeiro, v. 33, 1986. p. 541 - 632.

INTERNATIONAL PLANT NAME INDEX (IPNI). Search plant names. Disponível em: <http:// http://www.ipni.org/ipni/plantnamesearchpage.do>. Acesso em: 08/08/2010.

IVANAUSKAS, N. M.; ASSIS, M. C. Formações florestais brasileiras. In: MARTINS, S. V. Ecologia de Florestas Tropicais do Brasil. Viçosa, 2009. p. 74 - 108.

INTERNATIONAL UNION FOR CONSERVATION OF NATURE AND NATURAL RESOURCES (IUCN) Red list of threatened species, 2008. Disponível em: <http://www.biodiversitas.org.br/floraBr/ iucn.pdf $>$. Acesso em: 15/06/2012.

JURINITZ, C. F.; JARENKOW, J. A. Estrutura do componente arbóreo de uma floresta estacional na Serra do Sudeste, Rio Grande do Sul, Brasil. Revista Brasileira de Botânica, São Paulo, v. 26, n. 4, p. $475-487,2003$.

KILCA, R. V. Alguns aspectos florísticos e estruturais de uma floresta de galeria no sul da Planície Costeira do Rio Grande do Sul. 80 f. Monografia (Graduação em Ciências Biológicas) - Universidade Federal de Pelotas, Pelotas, 2002.

KÖPPEN, W. P. Climatologia: con un studio de los climas de la tierra. Mexico: Fondo de Cultura Economica, 1948. 478 p.

LASKA, M. S. Structure of understory shrub assemblages in a adjacent secondary and old growth tropical wet forests, Costa Rica. Biotropica, Washington, v. 29, p. 29 - 37, 1997.

LONGHI, S. J.; BRENA, D. A.; SCIPIONI, M. C.; GIACOMOLLI, L. Z.; DELIBERALI, G.; LONGHI, R. V.; MASTELLA, T. Caracterização fitossociológica do estrato arbóreo em um remanescente de Floresta Estacional Semidecidual em Montenegro, RS. Ciência Rural, Santa Maria, v. 38, n. 6, p. 1630 1638, 2008.

MANTOVANI, W. Conceituação e fatores condicionantes. In: SIMPÓSIO SOBRE MATA CILIAR, 1989, Campinas. Anais... Campinas: Fundação Cargill, 1989. p. 11 - 19.

MIGUEL, A.; MARIMON, B. S.; MARACAHIPES, L.; OLIVEIRA, E. A.; MARIMON JR., B. H. Mudanças na estrutura da vegetação lenhosa em três porções da mata de galeria do Córrego Bacana (1999-2006), Nova Xavantina, MT. Revista Árvore, Viçosa, v. 35, n. 3, p. 725 - 735, 2011.

MORO, M. F.; MARTINS, F. R. Métodos de levantamento do componente arbóreo-arbustivo. In: FELFINI, J. M.; EISENLOHR, P. V.; MELO, M. M. R. F.; ANDRADE, L. A. A.; NETO, J. A. A. M. Fitossociologia no Brasil: métodos e estudos de caso. Viçosa, 2011. p. 174 - 212.

OLIVEIRA-FILHO, A. T.; ALMEIDA, R. J.; MELLO, J. M.; GAVILANES, M. L. Estrutura fitossociológica e variáveis ambientais em um trecho de mata ciliar do córrego dos Vilas Boas, Reserva Biológica do Poço Bonito, Lavras (MG). Revista Brasileira de Botânica, São Paulo, v. 17, n. 1, p. 67 85, 1994.

OLIVEIRA FILHO, A. T.; FONTES, M. A. L. Patterns of floristic differentiation among Atlantic Forests in Southeastern Brazil, and the influence of climate. Biotropica, Washington, v. 32, n. 4, p. 793 - 810, 2000 .

PAULA, A.; SILVA, A. F.; SOUZA, A. L.; SANTOS, F. A. M. Alterações florísticas ocorridas num período de quatorze anos na vegetação arbórea de uma Floresta Estacional Semidecidual em Viçosa, MG. Revista Árvore, Viçosa, v. 26, n. 6, p. 743 - 749, 2002.

PINTO, S. I. C.; MARTINS, S. V.; SILVA, A. G.; BARROS, N. F.; DIAS, H. C. T.; SCOSS, L. M. Estrutura do componente arbustivo-arbóreo de dois estádios sucessionais de Floresta Estacional 
Semidecidual na Reserva Florestal Mata do Paraíso, Viçosa, MG, Brasil. Revista Árvore, Viçosa, v. 31, n. 5, p. $823-833,2007$.

PREFEITURA MUNICIPAL DE PELOTAS. Mapa Temático: Bacias Hidrográficas. III Plano Diretor. Pelotas, 2006. Escala 1:60.000.

RIO GRANDE DO SUL a. Decreto n. 42.099, de $1^{\circ}$ de janeiro de 2003. Lista final das espécies da flora ameaçadas. Diário Oficial do Estado, Porto Alegre, RS, $1^{\circ}$ jan. 2003. Disponível em: $<$ http://www.fzb.rs.gov.br/downloads/flora_ameacada.pdf>. Acesso em: 12/06/2012.

RIO GRANDE DO SUL b. Lei Estadual n. 11.895, de 28 de março de 2003. Declara integrante do patrimônio cultural do Estado o Arroio Pelotas. Diário Oficial do Estado, Porto Alegre, RS, 23 mar. 2003. Disponível em: <http://www3.al.rs.gov.br/FileRepository/repLegis/Arquivos/11.895.pdf>. Acesso em: 06/08/2012.

RUSCHEL, A. R.; MANTOVANI, M.; REIS, M. S.; NODARI, R. O. Caracterização e dinâmica de duas fases sucessionais em floresta secundária da Mata Atlântica. Revista Árvore, Viçosa, v. 33, n. 1, p. 101 $115,2009$.

SAWCZUK, A. R.; FILHO, A. F.; DIAS, A. N.; WATZLAWICK, L. F.; STEPKA, T. F. Alterações na estrutura e na diversidade florística no período 2002-2008 de uma Floresta Ombrófila Mista Montana do centro-sul do Paraná, Brasil. Floresta, Curitiba, v. 42, n. 1, p. 1 - 10, 2012.

SHEPHERD, G. J. Fitopac 1: Manual do Usuário. Campinas, Unicamp, 1995. 17 p.

SIMINSKI, A.; MANTOVANI, M.; REIS, M. S.; FANTINI, A. C. Sucessão florestal secundária no município de São Pedro de Alcântara, litoral de Santa Catarina: estrutura e diversidade. Ciência Florestal, Santa Maria, v. 14, n. 1, p. 21 - 33, 2004.

SOUZA, C. A. Estrutura do componente arbóreo de floresta pluvial subtropical na Serra dos Tapes, sul do Rio Grande do Sul. 54 f. Dissertação (Mestrado em Botânica) - Universidade Federal do Rio Grande do Sul, Porto Alegre, 2001.

TABARELLI, M.; VILLANI, J. P. MANTOVANI, W. Aspectos da sucessão secundária em trecho de Floresta Atlântica no Parque Estadual da Serra do Mar. Revista Instituto Florestal, São Paulo, v. 5, n. 1, p. 99 - 112, 1993.

TABARELLI, M.; MANTOVANI, W. A regeneração de uma floresta tropical Montana após corte e queima (São Paulo, Brasil). Revista Brasileira de Biologia, São Carlos, v. 59, n. 2, p. 239 - 250, 1999.

TABARELLI, M.; PERES, C. A. Abiotic and vertebrate seed dispersal in the Brazilian Atlantic Forest: implications for forest regeneration. Biological Conservation, Boston, v. 106, p. 165 - 176, 2002.

VACCARO, S.; LONGHI, S. J.; BRENA, A. Aspectos da composição florística e categorias sucessionais do estrato arbóreo de três subseres de uma Floresta Estacional Decidual no Município de Santa Tereza, RS. Ciência Florestal, Santa Maria, v. 9, n. 1, p. 1 - 18, 1999.

VENZKE, T. S. Estudo das matas ciliares da Bacia Hidrográfica do Arroio Pelotas, RS, Brasil. 54 f. Monografia (Especialização em Gestores Regionais em Recursos Hídricos) - Universidade Federal de Pelotas, Pelotas, 2009.

Florística de comunidades arbóreas no Município de Pelotas, Rio Grande do Sul. Rodriguesia, v. 63 , n. 3 , p. $571-578,2012$.

VIANA, V. M. Conservação da biodiversidade de fragmentos de florestas tropicais em paisagens intensamente cultivadas. In: Conservation International do Brasil/Universidade Federal de Minas Gerais/University of Florida. Abordagens interdisciplinares para a conservação da biodiversidade e dinâmica do uso da terra no Novo Mundo. Belo Horizonte/Gaisnesville, 1995. p. 135 - 154.

WHITMORE, T. C. An introduction to tropical rain forest. New York: Oxford University Press, 2006. $226 \mathrm{p}$. 
